
\title{
28 Research Suare \\ Effect of Obesity on Mortality in Pulmonary Hypertension, Does Obesity Paradox Exist?
}

Raju M Reddy ( $\square$ reddyr@ohsu.edu )

Oregon Health \& Science University https://orcid.org/0000-0002-3269-0136

Akram Khan

Oregon Health \& Science University

Saminder Singh

University of Florida College of Medicine

Bashar Alzghoul

University of Florida College of Medicine

Sherie Gause

Oregon Health \& Science University

Nalini Colaco

Oregon Health \& Science University

Jeffrey Robinson

Oregon Health \& Science University

Yazan Zayed

University of Florida College of Medicine

\section{Research Article}

Keywords: obesity, pulmonary hypertension, mortality, body mass index

Posted Date: May 26th, 2021

DOI: https://doi.org/10.21203/rs.3.rs-540969/v1

License: (c) (1) This work is licensed under a Creative Commons Attribution 4.0 International License.

Read Full License 


\section{Abstract}

Obesity is reported to have a protective effect on mortality in pulmonary hypertension (PH), a phenomenon known as obesity paradox. However, the data is conflicting with some studies showing decreased mortality while other studies found no effect of obesity on mortality. Therefore, we performed a meta-analysis to examine the effect of obesity on mortality in $\mathrm{PH}$. Only patients with $\mathrm{PH}$ diagnosed by right heart catheterization were included. We also performed a sub-group analysis of subjects with precapillary PH only. A total of seven studies met the inclusion criteria with a sample size of 79,577 patients. Obese subjects had lower mortality compared to non-obese subjects in the mixed $\mathrm{PH}$ group (hazard ratio $0.67,95 \% \mathrm{Cl} 0.51-0.87, \mathrm{P}<0.00001$ ) and in the pre-capillary $\mathrm{PH}$ group (hazard ratio $0.74 ; 95 \% \mathrm{Cl} 0.58-0.96$; $\mathrm{P}<0.00001$ ). Body mass index $\geq 30 \mathrm{~kg} / \mathrm{m}^{2}$ may be associated with reduced mortality but these results must be interpreted with caution.

\section{Introduction}

Obese patients with left sided heart failure have higher survival rates compared to their non-obese counterparts, a phenomena known as obesity paradox [1]. Similar findings have been reported in patients with pre-capillary pulmonary hypertension $(\mathrm{PH})$ also but the association of obesity paradox with mortality in $\mathrm{PH}$ remains controversial. This relationship, if any, is not well understood clinically or physiologically.

\section{Methods}

To further examine this association, we sought to examine the effect of obesity on $\mathrm{PH}$ mortality by performing a meta-analysis using the Preferred Reporting Items for Systematic Reviews and MetaAnalyses Protocols (PRISMA) 2015 Statement guidelines [2]. A literature search utilizing major electronic databases including PubMed, Cochrane library, and Embase was performed using the MeSH term "obesity AND pulmonary hypertension". Only studies with hemodynamic data obtained by right heart catheterization and reported mortality outcomes were included. We used the generic inverse variance to calculate the pooled hazards ratio of mortality using random effects model.

After the final review by two authors (RR, $Y Z$ ), seven studies met inclusion criteria for the analysis of which four were prospective observational studies and three were retrospective registry-based studies. Two studies included subjects with pre-capillary $\mathrm{PH}$, post-capillary $\mathrm{PH}$ and combined pre and postcapillary $\mathrm{PH}[3,4]$, while the other five studies included only subjects with pre-capillary PH [5-9]. All studies classified obese individuals as those with body mass index $(\mathrm{BMI}) \geq 30 \mathrm{~kg} / \mathrm{m}^{2}$. Five studies $[3,6-$ 9] compared obese (BMI $\geq 30 \mathrm{~kg} / \mathrm{m}^{2}$ ) versus non-obese subjects while two studies $[4,5]$ compared obese $\left(\mathrm{BMI} \geq 30 \mathrm{~kg} / \mathrm{m}^{2}\right)$ versus normal weight subjects (BMI $\left.18-24.9 \mathrm{~kg} / \mathrm{m}^{2}\right)$. We performed a sensitivity analysis by including only studies that included patients with pre-capillary $\mathrm{PH}$. The main outcome was all-cause mortality.

\section{Results}


The final analysis included seven studies totaling 79,577 patients; 49,607 (62.3\%) were obese subjects defined as $\mathrm{BMI} \geq 30 \mathrm{~kg} / \mathrm{m}^{2}$, and $29,970(37.7 \%)$ non-obese or normal weight subjects. Obese subjects had significantly reduced mortality when compared to non-obese subjects in the mixed $\mathrm{PH}$ patient population (Hazard ratio $0.67,95 \% \mathrm{Cl} 0.51-0.87, \mathrm{P}<0.00001$ ) as well as in subjects with pre-capillary $\mathrm{PH}$ (Hazard ratio 0.74; 95\% Cl 0.58-0.96; $\mathrm{P}<0.00001$ ) (Figure A).

\section{Discussion}

Our study showed that obesity is present in $62.3 \%$ of subjects with $\mathrm{PH}$ and was associated with a significant reduction in mortality among subjects with both precapillary $\mathrm{PH}$ as well as combined pre and postcapillary PH when compared with non-obese subjects. This finding was consistent in all included studies except the study by Weatherald et al., who found no effect of obesity on mortality [8].

The mechanism of the protective effect of obesity on mortality in cardiovascular disease is unknown but a few hypotheses have been explored. Adiponectin, a hormone derived from adipocytes, is thought to play a protective role in cardiovascular diseases by decreasing inflammatory cytokines such as tumor necrosis factor a levels and inhibition of NF-K $\beta$ activity [10]. In a study by Kumada et al., low levels of adiponectin were associated with the development of coronary artery disease and myocardial infarction in humans [11]. Similarly, in animal models of PH, it has been shown that adiponectin is associated with reduced smooth muscle cell proliferation and decreasing levels of inflammatory cytokines [10]. Thus, patients who are normal or underweight may lose the protective effect of adiponectin. In addition, adipose tissue secretes apelin, an adipokine, which is known to promote vasodilation by activating nitric oxide synthase [12]. Whether the vasodilatory effect of apelin exits in obese $\mathrm{PH}$ patients remains unknown and is an area for further research.

While these findings are interesting, they should be interpreted with caution for several reasons. First, the hemodynamic variables between the two patient groups were different. In the three of the included studies $[5,6,9]$, obese patients tended to have higher pulmonary artery wedge pressures suggesting that they may have occult left ventricular diastolic dysfunction despite meeting criteria for pre-capillary $\mathrm{PH}$ at the time of right heart catheterization [13]. In addition, obese patients in the same studies had higher cardiac output $[5,8]$ and lower PVR $[5,8]$ which could also contribute to improved outcomes in these patients[14]. Second, rather than obesity conferring a protective effect, it is also possible that low BMI may simply be a manifestation of declining health due to right ventricular dysfunction. This decline in right ventricular failure may manifest as cardiac cachexia; characterized by congestion of hepatic and splanchnic beds, intestinal dysmotility and protein malabsorption [15]. Third, BMI does not capture body composition accurately. The implication that higher BMI is related to higher fat mass is not necessarily true. Thus, a better predictor of mortality could be the total fat mass or the pattern of distribution of fat (central vs. peripheral). In a study of heart failure patients by Sutter et al., a J-shaped mortality curve was seen where patients with the lowest $\mathrm{BMI}$ and higher $\mathrm{BMI}\left(\mathrm{BMI}>35 \mathrm{~kg} / \mathrm{m}^{2}\right)$ had higher mortality compared to the overweight BMI $25-35 \mathrm{~kg} / \mathrm{m}^{2}$ group [16]. On further analysis, it was found that having a higher lean body mass despite being overweight conferred a protective effect and that higher body fat 
percentage in the obese population was detrimental. A similar J-shaped mortality curve was also observed in patients with pre-capillary $\mathrm{PH}$ [8]. While these studies did not examine the body mass composition, it is possible that the morbidly obese $\mathrm{PH}$ patients who had a higher mortality had a higher fat mass percentage.

Our analysis is limited by its heterogeneity. Many potential reasons account for this. First, studies included used various definitions of $\mathrm{PH}$. To minimize the impact of the variation, we only included studies that reported hemodynamics obtained by right heart catheterization and also performed a sub-group analysis for patients with pre-capillary $\mathrm{PH}$. Second, three of the seven included studies were retrospective. Given that $\mathrm{PH}$ is a rare disease, data gathering is often limited to retrospective data from registries. Third, the confounding variables used in studies differed which could have affected the hazard ratios obtained when studying the impact of obesity in $\mathrm{PH}$ patients.

In summary, we found that obese $\mathrm{PH}$ patients had lower mortality compared to non-obese patients. This 'obesity paradox' in PH is a noteworthy finding and warrants further studies. Given the pathobiologic complexities of $\mathrm{PH}$, it is possible that there are different phenotypes of obesity that confer either protective or pathologic effects on pulmonary vascular disease. Future studies examining the association between $\mathrm{BMI}$ and $\mathrm{PH}$ may help better define this relationship by studying the effect of body composition and body fat distribution on outcomes in $\mathrm{PH}$. With the precise causal effects of obesity in $\mathrm{PH}$ being unknown, future registry-based studies could increase long term follow up of patients and closely track body composition to more precisely determine the effect of obesity in $\mathrm{PH}$.

\section{Declarations}

\section{Funding:}

none

\section{Conflicts of Interest:}

All authors declare that they have no conflicts of interests to declare related to this work

\section{Availability of Data and Material:}

Data available on request

\section{Authors' Contributions:}

Raju Reddy (data curation, conceptualization, methodology, investigation, writing - original draft, writing - reviewing and editing); Akram Khan (methodology, investigation, writing - original draft, writing reviewing and editing); Saminder Singh (data curation, conceptualization, methodology, investigation, writing - original draft, writing - reviewing and editing); Bashar Alzghoul (methodology, investigation, writing - original draft, writing - reviewing and editing); Sherri Gause (methodology, investigation, writing 
- original draft, writing - reviewing and editing); Nalini Colaco (methodology, investigation, writing original draft, writing - reviewing and editing); Jeffrey Robinson (data curation, conceptualization, methodology, investigation, writing - original draft, writing - reviewing and editing); Yazan Zayed (data curation, conceptualization, methodology, investigation, writing - original draft, writing - reviewing and editing)

\section{References}

1. Sharma A, Lavie CJ, Borer JS, Vallakati A, Goel S, Lopez-Jimenez F, Arbab-Zadeh A, Mukherjee D, Lazar JM. Meta-analysis of the relation of body mass index to all-cause and cardiovascular mortality and hospitalization in patients with chronic heart failure. Am. J. Cardiol. [Internet] Elsevier Inc.; 2015 [cited 2021 Apr 17]; 115: 1428-1434Available from: https://pubmed.ncbi.nlm.nih.gov/25772740/.

2. Kamioka H. Preferred reporting items for systematic review and meta-analysis protocols (prisma-p) 2015 statement. Japanese Pharmacol. Ther. 2019; 47: 1177-1185.

3. Zafrir B, Adir Y, Shehadeh W, Shteinberg M, Salman N, Amir O. The association between obesity, mortality and filling pressures in pulmonary hypertension patients; The "obesity paradox." Respir. Med. [Internet] Elsevier Ltd; 2013; 107: 139-146Available from:

http://dx.doi.org/10.1016/j.rmed.2012.10.019.

4. Trammell AW, Hemnes AR, Tseng V, Shah AJ, Phillips LS, Hart CM. Influence of Body Weight and Diabetes Mellitus in Patients With Pulmonary Hypertension. Am. J. Cardiol. [Internet] Elsevier Inc.; 2020; 134: 130-137Available from: https://doi.org/10.1016/j.amjcard.2020.07.062.

5. Min J, Feng R, Badesch D, Berman-Rosenzweig E, Burger C, Chakinala M, De Marco T, Feldman J, Hemnes A, Horn EM, Lammi M, Mathai S, McConnell JW, Presberg K, Robinson J, Sager J, Shlobin O, Simon M, Thenappan T, Ventetuolo C, Al-Naamani N. Obesity in pulmonary arterial hypertension the pulmonary hypertension association registry. Ann. Am. Thorac. Soc. 2021; 18: 229-237.

6. Poms AD, Turner M, Farber HW, Meltzer LA, McGoon MD. Comorbid conditions and outcomes in patients with pulmonary arterial hypertension: A reveal registry analysis. Chest [Internet] The American College of Chest Physicians; 2013; 144: 169-176Available from: http://dx.doi.org/10.1378/chest.11-3241.

7. Strange G, Lau EM, Giannoulatou E, Corrigan C, Kotlyar E, Kermeen F, Williams T, Celermajer DS, Dwyer N, Whitford H, Wrobel JP, Feenstra J, Lavender M, Whyte K, Collins N, Steele P, Proudman S, Thakkar V, Keating D, Keogh A. Survival of Idiopathic Pulmonary Arterial Hypertension Patients in the Modern Era in Australia and New Zealand. Hear. Lung Circ. [Internet] Australian and New Zealand Society of Cardiac and Thoracic Surgeons (ANZSCTS) and the Cardiac Society of Australia and New Zealand (CSANZ); 2018; 27: 1368-1375Available from: http://dx.doi.org/10.1016/j.hlc.2017.08.018.

8. Weatherald J, Huertas A, Boucly A, Guignabert C, Taniguchi Y, Adir Y, Jevnikar M, Savale L, Jaïs X, Peng M, Simonneau G, Montani D, Humbert M, Sitbon O. Association Between BMI and Obesity With Survival in Pulmonary Arterial Hypertension. Chest [Internet] Elsevier Inc; 2018; 154: 872881Available from: https://doi.org/10.1016/j.chest.2018.05.006. 
9. Frank RC, Min J, Abdelghany M, Paniagua S, Bhattacharya R, Bhambhani V, Pomerantsev E, Ho JE. Obesity Is Associated With Pulmonary Hypertension and Modifies Outcomes. J. Am. Heart Assoc. 2020; 9: e014195.

10. Perrotta F, Nigro E, Mollica M, Costigliola A, D’agnano V, Daniele A, Bianco A, Guerra G. Pulmonary hypertension and obesity: Focus on adiponectin [Internet]. Int. J. Mol. Sci. MDPI AG; 2019 [cited 2021 Mar 31].Available from: https://pubmed.ncbi.nlm.nih.gov/30791536/.

11. Kumada M, Kihara S, Sumitsuji S, Kawamoto T, Matsumoto S, Ouchi N, Arita Y, Okamoto Y, Shimomura I, Hiraoka H, Nakamura T, Funahashi T, Matsuzawa Y. Association of hypoadiponectinemia with coronary artery disease in men. Arterioscler. Thromb. Vasc. Biol. [Internet] Arterioscler Thromb Vasc Biol; 2003 [cited 2021 Mar 31]; 23: 85-89Available from: https://pubmed.ncbi.nlm.nih.gov/12524229/.

12. Japp AG, Cruden NL, Amer DAB, Li VKY, Goudie EB, Johnston NR, Sharma S, Neilson I, Webb DJ, Megson IL, Flapan AD, Newby DE. Vascular Effects of Apelin In Vivo in Man. J. Am. Coll. Cardiol. [Internet] J Am Coll Cardiol; 2008 [cited 2021 Apr 1]; 52: 908-913Available from: https://pubmedncbi-nlm-nih-gov.liboff.ohsu.edu/18772060/.

13. Robbins IM, Hemnes AR, Pugh ME, Brittain EL, Zhao DX, Piana RN, Fong PP, Newman JH. High prevalence of occult pulmonary venous hypertension revealed by fluid challenge in pulmonary hypertension. Circ. Hear. Fail. [Internet] Lippincott Williams and Wilkins; 2014 [cited 2021 Mar 31]; 7: 116-122Available from: https://pubmed.ncbi.nlm.nih.gov/24297689/.

14. McLaughlin V V., Shillington A, Rich S. Survival in primary pulmonary hypertension: The impact of epoprostenol therapy. Circulation [Internet] Circulation; 2002 [cited 2021 Mar 31]; 106: 14771482Available from: https://pubmed.ncbi.nlm.nih.gov/12234951/.

15. Melenovsky V, Kotrc M, Borlaug BA, Marek T, Kovar J, Malek I, Kautzner J. Relationships between right ventricular function, body composition, and prognosis in advanced heart failure. J. Am. Coll. Cardiol. [Internet] J Am Coll Cardiol; 2013 [cited 2021 Mar 31]; 62: 1660-1670Available from: https://pubmed.ncbi.nlm.nih.gov/23916933/.

16. De Schutter A, Lavie CJ, Kachur S, Patel DA, Milani R V. Body composition and mortality in a large cohort with preserved ejection fraction: Untangling the obesity paradox. Mayo Clin. Proc. [Internet] Elsevier Ltd; 2014 [cited 2021 Apr 1]; 89: 1072-1079Available from: https://pubmed-ncbi-nlm-nihgov.liboff.ohsu.edu/25039037/.

\section{Figures}




\subsubsection{All PHTN}

Poms 2013

Zafrir 2013

Strange 2018

Weatherald 2018

Frank 2020

Min 2020

Tramell 2020

Subtotal $(95 \% \mathrm{Cl})$

$\begin{array}{rrr}-0.3147 & 0.0916 & 15.7 \% \\ -1.6094 & 0.3537 & 7.8 \% \\ -0.0834 & 0.0285 & 16.8 \% \\ 0.1484 & 0.1295 & 14.6 \% \\ -0.2614 & 0.056 & 16.5 \% \\ -0.844 & 0.2189 & 11.7 \% \\ -0.5798 & 0.0092 & 16.9 \% \\ & & \mathbf{1 0 0 . 0} \%\end{array}$

$0.73[0.61,0.87] 2013$

$0.20[0.10,0.40] 2013$

$0.92[0.87,0.97] 2018$

$1.16[0.90,1.50] 2018$

$0.77[0.69,0.86] 2020$

$0.43[0.28,0.66] 2020$

$0.56[0.55,0.57] 2020$

$0.67[0.51,0.87]$

Heterogeneity: $\operatorname{Tau}^{2}=0.11 ; \mathrm{Ch}^{2}=341.49, \mathrm{df}=6(\mathrm{P}<0.00001) ; \mathrm{I}^{2}=98 \%$

Test for overall effect: $Z=3.03(P=0.002)$

\subsubsection{Pre-capillary PHTN}

Poms 2013

Strange 2018

Weatherald 2018

Frank 2020

Min 2020

Subtotal $(95 \% \mathrm{Cl})$

$\begin{array}{rrr}-0.3147 & 0.0916 & 21.6 \% \\ -0.0834 & 0.0285 & 24.0 \% \\ 0.1484 & 0.1295 & 19.5 \% \\ -0.5621 & 0.1094 & 20.7 \% \\ -0.844 & 0.2189 & 14.2 \% \\ & & \mathbf{1 0 0 . 0} \%\end{array}$

$0.73[0.61,0.87] 2013$ $0.92[0.87,0.97] 2018$ $1.16[0.90,1.50] 2018$ $0.57[0.46,0.71] 2020$ $0.43[0.28,0.66] 2020$ $0.74[0.58,0.96]$

Heterogeneity: $\operatorname{Tau}^{2}=0.07 ; \mathrm{Chi}^{2}=37.60, \mathrm{df}=4(\mathrm{P}<0.00001) ; \mathrm{I}^{2}=89 \%$

Test for overall effect: $Z=2.30(P=0.02)$

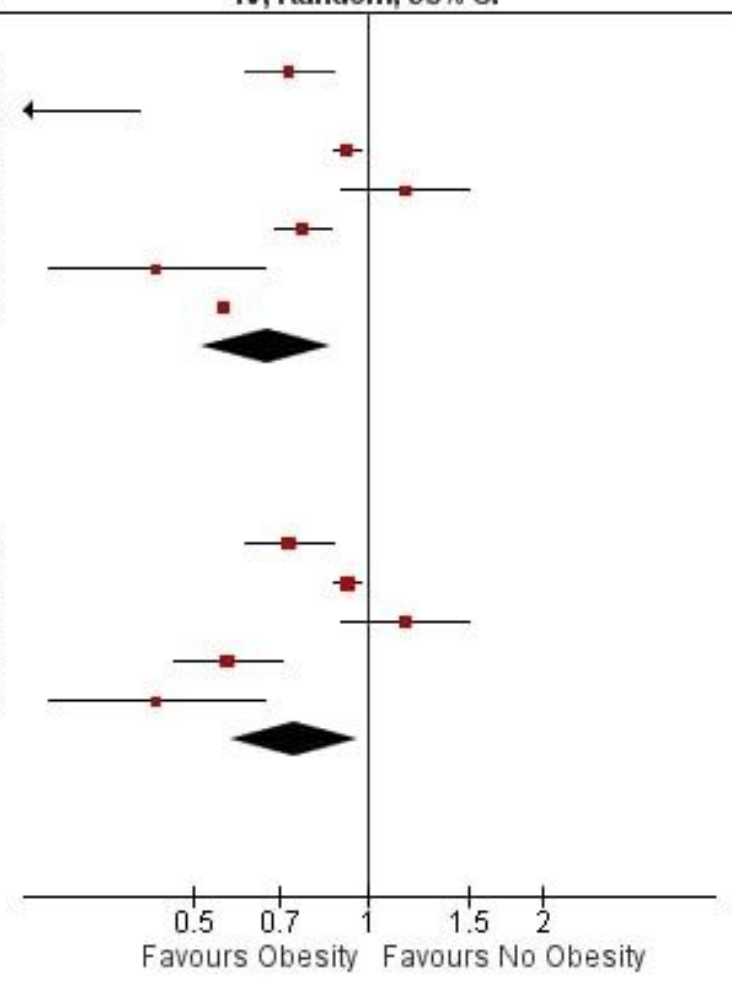

\section{Figure 1}

Forest plot for mortality amongst obese versus non-obese subjects in combined pre- and post- capillary pulmonary hypertension and pre-capillary pulmonary hypertension only. 